\title{
Voltage Collapse Enhancement and Loss Reduction by Reactive Power Reserve
}

\author{
A.Subramanian \\ V.R.S College of Engineering and Technology \\ Department of Electrical and Electronics Engineering \\ Arasur, Tamil Nadu -607107
}

\author{
Dr. G.Ravi \\ Pondicherry Engineering College \\ Department of Electrical and Electronics Engineering \\ Pillaichavadi Puducherry, \\ Puducherry
}

\begin{abstract}
Now a day modern power industry is facing the problem of voltage instability due to stressed conditions and heavy load .The main cause for the voltage instability is the in sufficient reactive power at the load buses of the system. This paper deals with the problem of reactive power reserve management and voltage collapse point enhancement and loss reduction. Simulation is performed on the IEEE30 and 57 bus systems under Neuton Rapson (NR) and particle swarm optimization (PSO) methods. Additional reactive power injected by the optimally placed FACTS device (SVC) in the load bus reduced the reactive power generation of the generators and decreased the losses. The reduced reactive power generation of the generators increased the reactive power reserve management and enhanced the voltage collapse point. It is visible from the result that the optimal sizing and positioning of SVC in the PSO method is improving the reactive power reserve and enhances the voltage collapse point in a better level comparatively NR method.
\end{abstract}

\section{Keywords}

Voltage Instability; Voltage Collapse; Maximum loadability point; FACTS Devices; Reactive power reserve; PSO; NR

\section{INTRODUCTION}

Voltage collapse is the phenomenon of the voltage instability in the power system. This happen when the system is gradually loaded to the maximum load condition in such a way that the voltage magnitude to decrease gradually [1].Voltage magnitude alone will not give a good indication for voltage collapse point or maximum loadability limit or voltage stability limit [2].An effective voltage collapse point index indicates how far the current operating condition is from voltage collapse and witch buses are the most vulnerable. Many voltage collapse prediction methods have been presented to identify the distance to voltage collapse.

Antonio et al. [3] proposed a voltage collapse index known as full sum QV based on $\partial Q i / \partial V i$. The main problem is that the voltage, on its own, is often a poor indicator of voltage instability. Voltage stability index determines how far from voltage collapse the system is, and can be used for activating pre defined protective measures at the most critical buses in the system. In general, loads are dependent on bus voltage. Also, it is known that load dynamics greatly affect the voltage stability. Since voltage dependent loads play a very important role in voltage stability. The static voltage stability is primarily associated with the reactive power support. Voltage stability index proposed in [4] is based on the facts that with increase in load at a load bus the diagonal elements $(\partial \mathrm{Q} i / \partial \mathrm{Vi}$ and $\partial \mathrm{Pi} / \partial \delta \mathrm{i})$ of the load flow Jacobian matrix reduces. This reduction is quite considerable as the voltage collapse point is approached. The proposed index uses this change in value of diagonal elements $\partial \mathrm{Q} i / \partial \mathrm{Vi}$ and $\partial \mathrm{Pi} / \partial \delta \mathrm{i}$ of the Jacobian matrix. The bus voltage stability index proposed in [4] has been used in this work to determine the voltage collapse distance, because the threshold value is always 0.5 which is given in equation (1). Voltage collapse typically occurs on power system while it is heavily stressed. It may or may not be initiated by a disruption, but is usually characterized by shortage of fast-acting reactive reserves.

Reactive power demand generally increases with load increase. The fast reactive sources are generators, synchronous condensers and power electronics-based flexible ac transmission systems (FACTS) devices. During voltage emergencies, reactive resources should be activated to boost transmission voltage levels. This action will increase the reactive reserve and decrease the losses of transmission lines. It is wise to keep enough reserves in order to improve the voltage stability margin. Reactive power reserve has always been linked with voltage stability. Author in [5] discusses a reactive management program for a practical power system. The author discusses a method to supply reactive power during demands by installing properly sized and located capacitor banks which will allow generating units to operate at or near unity power factor. However, it is a cost-intensive proposition. Besides, this strategy is not always very effective since not all the shunt capacitors are fully utilized. In this paper FACTS devices (SVC) is optimally incorporated in the buses to adjust the reactive power and maintain the voltage within the limit by improving the reactive reserve when the load is increased gradually. The reactive power reserve of the generator is given in equation (2).

$$
I i=\frac{\partial P i / \partial \delta i}{\sum_{\substack{j=1 \\ j \neq i}}^{N} B i j V j}
$$

$$
Q g \max r e s=Q g \max -Q g
$$

\section{STATIC VAR COMPENSATOR}

Static Var Compensator (SVC) as in [6] is one of the simple controllers based on Power Electronics and other static devices known as FACTS (Flexible AC Transmission Systems) Controllers which could be used to increase the capacity and the flexibility of a transmission network. The electric power quality at the low voltage level is affected, in great deal, by the disturbance due to switching actions or faults that happens in the power system at the middle and low voltage levels. $\mathrm{SVC}$ is one of the best devices to improve the voltages profile 
by providing the necessary reactive power in the load buses. Claudio et al. [7] proposed the steady state models of SVC and TCSC for the voltage collapse point improvement problem. In this the modeling of the devices and selecting the ranges are found difficult. C.J.Parkar in [8] used many devices to achieve reactive power reserve, it increased the installation cost. Muhammad Waseem Younas and Suhail A. Qureshi in his work [9] installed SVC of different ranges to increase the voltage collapse point. He concluded that SVCs of smaller ranges are suitable to use in the compensation. FACTS devices based on thyristor controlled reactor (TCR) such as static var compensators (SVC) and thyristor controlled series capacitor (TCSC) are being used by several electric utilities to compensate their system [10][11]. SVC is more suited in reactive power adjustment when connected in the load buses than in the lines with the susceptance property. The basic structure of SVC is shown in figure1.In the steady state model if an SVC is connected to a particular bus ' 1 ' then the injected power at that bus is given by

$$
Q i=Q s v c
$$

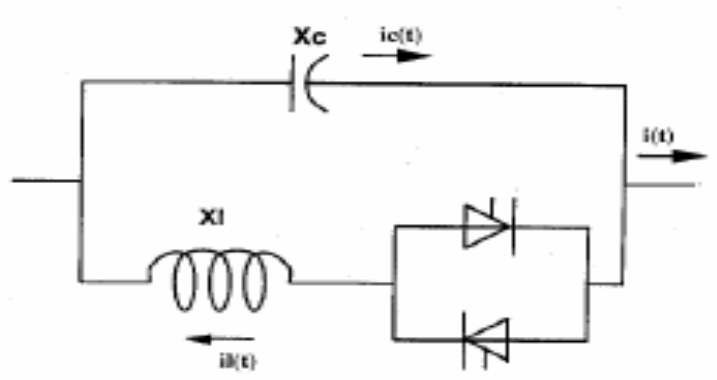

Fig1: Basic model of SVC

\section{PARTICLE SWARM OPTIMIZATION}

Particle swarm optimization (PSO) method is a member of wide category of population based methods for solving the optimization problems. Each particle in PSO moves through the search space with an adaptable velocity that is dynamically modified according to its own moving experience with the other particles. In PSO each particle strives to improve themself by imitating traits from their successful peers. Further, each particle has a memory and hence it is capable of remembering the best position in the search space ever visited by it. The position corresponding to the best fitness is known as pbest and the overall best out of all the particles in the population is called gbest.

The features of the searching procedure can be summarized as follows [12]:

- Initial positions of pbest and gbest are different. However, using the different direction of pbest and gbest, all agents gradually get close to the global optimum.

- The modified value of the agent position is continuous. However, the method can be applied to the continuous and discrete problem using grids and its velocity.

- There are no inconsistencies in searching procedures even if continuous and discrete state variables are utilized with continuous grid positions and velocities. The modified velocity and position of each particle can be calculated using the current velocity and the distances from the pbest $t_{\mathrm{j}, \mathrm{g}}$ to gbest $_{\mathrm{g}}$ as shown in the following formulas [13]:

$$
\begin{aligned}
& v_{j, g}^{(t+1)}=w \times v_{j, g}^{(t)}+c_{1} \times r_{1}() \times\left(p_{\text {best }_{j, g}}-x_{j, g}^{(t)}\right)+\ldots \\
& C_{2} \times r_{2}() \times\left(g_{\text {best }_{g}}-x_{j, g}^{(t)}\right) \\
& x_{j, g}^{(t+1)}=x_{j, g}^{(t)}+v_{j, g}^{(t+1)} \\
& \text { with } \mathrm{j}=1,2 \ldots \mathrm{n} \text { and } \mathrm{g}=1,2, \ldots, \mathrm{m}
\end{aligned}
$$

Where $\mathrm{n}=$ number of particles in the swarm; $\mathrm{m}=$ number of components for the vectors $\mathrm{v}_{\mathrm{j}}$ and $\mathrm{x}_{\mathrm{j}} ; \mathrm{t}=$ number of iterations (generations); $v_{j, g}^{(t)}=$ the $\mathrm{g}_{\mathrm{th}}$ component of the velocity of particle' j' at iteration't'. The range of velocity of component is given as

$\boldsymbol{v}_{g}^{\min } \leq \boldsymbol{V}_{j, g}^{(t)} \leq \boldsymbol{v}_{g}^{\max }$

$\mathrm{w}=$ inertia weight factor; $\mathrm{c} 1, \mathrm{c} 2=$ cognitive and social acceleration factors, respectively/

$\mathrm{r} 1, \mathrm{r} 2=$ random numbers uniformly distributed in the range $(0,1) ; X_{j, g}^{(t)}=$ the $\mathrm{g}_{\mathrm{th}}$ component of the position of particle' j' at iteration $\mathrm{t}$; pbest $_{\mathrm{j}}=$ pbest of particle $\mathrm{j}$; gbest $=$ gbest of the group. The $j_{\text {th }}$ particle in the swarm is represented by a' $d$ ' dimensional vector $x_{j}=x_{j, 1}, x_{j, 2}, \ldots, x_{j, d}$ and its rate of position change (velocity) is denoted by another

'd' dimensional vector $v_{j}=v_{j, 1}, v_{j, 2}, \ldots, v_{j, d}$. The best previous position of the $j_{t h}$ particle is represented as Pbest $_{j}=$ Pbest $_{j, 1}$, Pbest $_{j, 2}, \ldots$, Pbest $_{j, d}$.

The index of best particle among all of the particles in the swarm is represented by the gbest $_{\mathrm{g}}$. In PSO, each particle moves in the search space with a velocity according to its own previous best solution and its group's previous best solution. The velocity update in a PSO consists of three parts; namely momentum, cognitive and social parts. The balance among these parts determines the performance of a PSO algorithm. The parameters $c_{1}$ and $c_{2}$ determine the relative pull of pbest and gbest and the parameters $r_{1}$ and $r_{2}$ help in stochastically varying these pulls. In the above equations, superscripts denote the iteration number. In this work $\mathrm{C}_{1}$ and $\mathrm{C}_{2}$ are selected as 2.5 and 1.5 respectively, rand 1 and rand 2 are randomly selected between $(0,1)$ the inertia weight calculated 


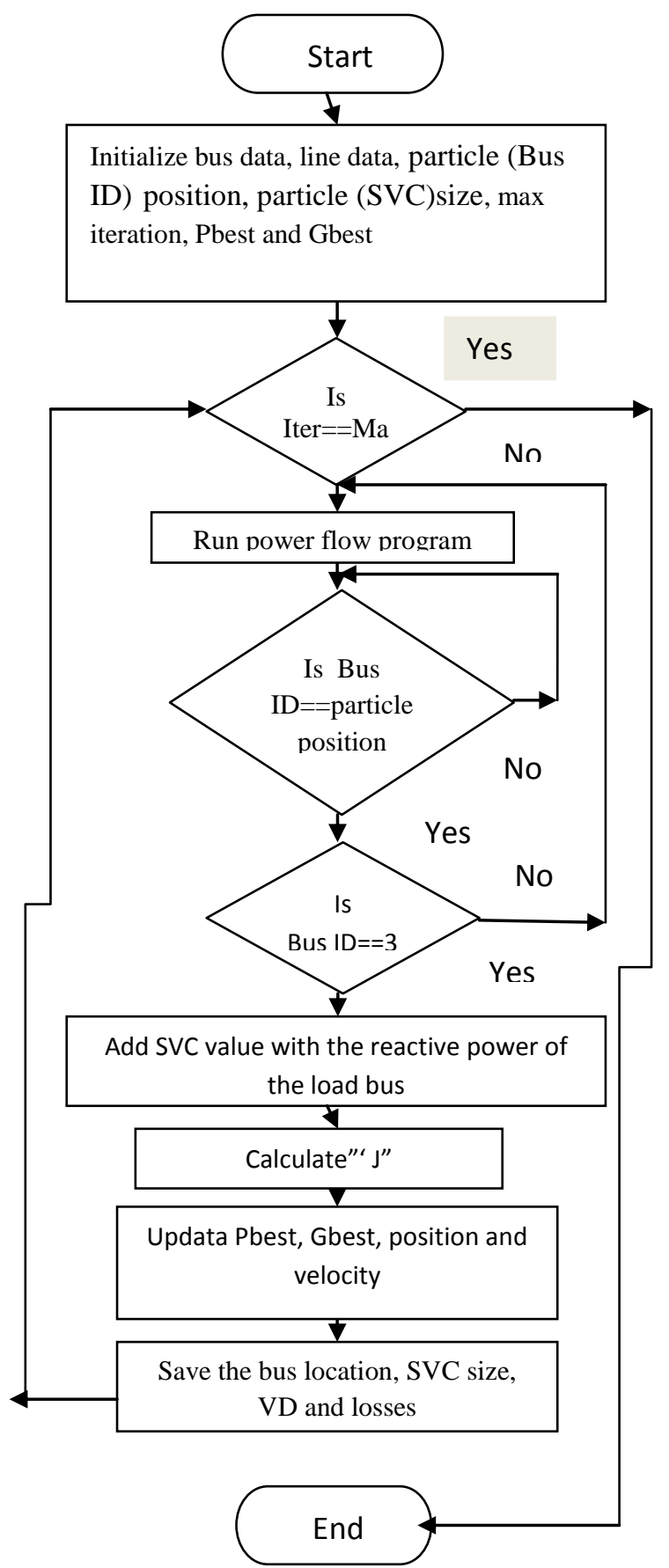

Fig 2: Flow chart of the PSO Algorithm

using the formula (7) as in [14]. Swarm Size is 10 and iteration 100. Y.Del.Valle in [15] used PSO to locate STATCOM to improve the voltage stability and showed good convergence and improved voltage stability.

$W=\frac{W_{\max -} W_{\min }}{\text { iter }_{\max }} \times$ iter

\section{PROBLEM FORMULATION}

The objective function ' $\mathrm{J}$ ' is to minimize the voltage deviation, real and reactive power losses. The real and reactive power loss calculations are as in [16]. The active and reactive power losses of the transmission network depend on $R i j \quad X i j$,

$Z i j$ and $\Delta V_{i j}$. Voltage drop $\Delta V_{i j}$ is the drop across the line segment connecting bus ' $\mathrm{i}$ ' and ' $\mathrm{j}$ '. When the voltage along the line changes, the real and reactive power losses also fluctuate.

$$
J=p f 1\left(\sum_{j=1}^{N}|V j-V r e f|^{2}\right)+p f 2\left(\sum_{i=1}^{N} \sum_{j=1}^{N} \Delta \mathrm{V}_{i j}^{2} \frac{R_{i j}}{Z_{i j}}\right)+\operatorname{pf} 3\left(\sum_{i=1}^{N} \sum_{j=1}^{N} \Delta \mathrm{V}^{2} i j \frac{X_{i j}}{Z_{i j}}\right)
$$

Where $R i j$ is the resistance $X i j$ is the reactance and $Z i j$ is the impedance of the line connecting bus ' $i$ ' and ' $j$ ', pf1,pf2 and pf3 are the penalty factors, $V_{j}$ is the $j_{t h}$ bus voltage and $V_{r e f}$ is the reference (specified) bus voltage.

The minimization problem is subject to the following equality and inequality Constraints:

$$
\begin{aligned}
& \text { (i) Load Flow Constraints } \\
& P i=V i \sum_{j=1}^{N} V j\left(G_{i j} \cos \theta_{i j}+\mathrm{B}_{i j} \sin \theta_{i j}\right)=0 \\
& Q i=V i \sum_{j=1}^{N} V j\left(G_{i j} \sin \theta_{i j}-B_{i j} \cos \theta_{i j}\right)=0
\end{aligned}
$$

where 'i' and ' $\mathrm{j}$ ' are buses and $\mathrm{N}=$ number of buses

(ii) Voltage Constraints:

$$
V_{i}^{\min \leq V_{i \leq}} V_{i}^{\max }
$$

(iii) Reactive Power Generation Limit:

$$
Q_{g i}^{\min } \leq Q_{g i} \leq Q_{g i}^{\max }
$$

(vi) Transmission line flow limit:

$$
S_{i \leq S_{i}^{\max }}
$$

(v) Size of the SVC

$$
-200 M V A R \leq Q s v c \leq 200 M V A R
$$




\section{SIMULATION RESULTS}

Simulations are carried out on IEEE 30 and 57 bus systems. The aim of the simulations is to provide the reactive power reserve and to enhance the proximity to voltage collapse point for increasing the maximum load ability point. For this purpose, the system load was gradually increased from the base case. Because of the similarity in the output wave forms only few are shown.

\section{Case 1:IEEE30 bus Systems}

The system was loaded from its base case up to load factor (LF) of 1.4 and with an X/R ratio of 4, in (Neuton Rapson) NR and PSO methods. Table 1 shows the total real and reactive power generation $\left(\mathrm{P}_{\mathrm{gT}}, \mathrm{Q}_{\mathrm{gT}}\right)$ of the system, individual generators reactive power generation $\left(\mathrm{Q}_{\mathrm{g} 2}, \mathrm{Q}_{\mathrm{g} 5} \cdot \mathrm{Q}_{\mathrm{g} 8}, \mathrm{Q}_{\mathrm{g} 11}, \mathrm{Q}_{\mathrm{g} 13}\right)$, total real and reactive power losses $\left(\mathrm{P}_{\text {Tloss }}, \mathrm{Q}_{\text {Tloss }}\right), \mathrm{SVC}$ size and bus location. In PSO method the reactive power generation is lesser than the NR method for the proper location and size of SVC. It is approximately 20 percent from the maximum reactive power limit. The real and reactive power losses are 0.415 MW and 3 MVAR respectively in PSO method which is comparatively lesser than the NR method. The different SVC size and bus locations shown in the table 1 under various load are reducing the reactive power generation and total real and reactive power losses in the 30 bus system.

Voltage under various load conditions in NR and PSO method are given in table 3 figures (3-7) shows the voltage profile bar chart. When the load is increased from its base value to $1.3 \mathrm{LF}$ in NR method the buses 5, 24,25,26,29 and 30 are going out of voltage level and also generator 5, 8 and 11 are violating their $\mathrm{Q}_{\text {gen }}$ limit. When the load is increased in PSO method the voltage is well within the specified level and none of the generators are violating which is below the limit in NR method. The indices and power factor of the system buses under loaded conditions are given in table5 and figures (8\&9) show the indices wave forms in the load buses. The bus voltage indices are always close to 0.498 not decreasing below the threshold value and the power factor is above 0.8. Table 2 gives the individual generators $\left(\mathrm{Q}_{\mathrm{g} 2}, \mathrm{Q}_{\mathrm{g} 5}, \mathrm{Q}_{\mathrm{g} 8}, \mathrm{Q}_{\mathrm{g} 11}, \mathrm{Q}_{\mathrm{g} 13}\right)$ reactive power generation, real and reactive power losses $\left(\mathrm{P}_{\text {Tloss }}\right.$, $\left.\mathrm{Q}_{\text {Tloss }}\right)$, system total real and reactive power generation $\left(\mathrm{P}_{\mathrm{gT}}\right.$, $\mathrm{Q}_{\mathrm{gT}}$ ),SVC size and bus position under generator outage condition in PSO method. It is not possible to operate under generator outage condition in NR method. Table 4 shows the voltage under generator outage contingency condition in PSO method. The reactive power injected by the SVC device placed in the load bus manages the reactive power requirement and voltage profiles under the generator outage condition.

\subsection{Case 2: IEEE 57 bus Systems}

The system was loaded from its base case to a load factor of 1.3 and with an X/R ratio of 4 in NR and PSO method the voltages are tabulated in table 7 . When the load is increased from its base value to $1.3 \mathrm{LF}$ in NR method buses 29, 30, 31 and 32 are going out of voltage level and also generator 9 is violating from its $\mathrm{Q}_{\mathrm{gen}}$ limit. When the load is increased in PSO method bus voltages are well within the specified limit and none of the generators are violating. Table 6 shows the reactive power generation of individual generators $\left(\mathrm{Q}_{\mathrm{g} 2}, \mathrm{Qg} 3\right.$, Qg6, Qg8, Qg9, and Qg12), total real and reactive power losses $\left(\mathrm{P}_{\text {Tloss }}, \mathrm{Q}_{\text {Tloss }}\right)$, total real and reactive power generation $\left(\mathrm{P}_{\mathrm{Tg}}, \mathrm{Q}_{\mathrm{Tg}}\right)$ in the system, $\mathrm{SVC}$ size, bus position. It is clear that individual generators are generating lesser reactive power in PSO method than the NR method. For the SVC size of 115.785 MVAR at $15^{\text {th }}$ bus and 20 percent of reactive power generation has been reduced. The real and reactive power losses are reduced in PSO method and it is $1.065 \mathrm{MW}$ and 29.631MVAR respectively. The indices and the power factor of the system buses under loaded condition are given in table 8 . The bus voltage indices are not decreasing below the threshold value and also the power factor is above 0.8.Voltage variation and indices in load buses with load change are shown in figures (10-12) and 13 .

Table 1. Real and Reactive power Generation, losses SVC size and Bus No under various load condition in NR and PSO

\begin{tabular}{|c|c|c|c|c|c|c|c|c|c|c|c|c|}
\hline & $\mathrm{LF}$ & $\begin{array}{l}\text { Qg2 } \\
\text { (Mvar) }\end{array}$ & $\begin{array}{l}\text { Qg5 } \\
\text { (Mvar) }\end{array}$ & $\begin{array}{l}\text { Qg8 } \\
\text { (Mvar) }\end{array}$ & $\begin{array}{l}\text { Qg11 } \\
\text { (Mvar) }\end{array}$ & $\begin{array}{l}\text { Qg13 } \\
\text { (Mvar) }\end{array}$ & $\begin{array}{l}\mathrm{Qg}_{\mathrm{T}} \\
\text { (Mvar) }\end{array}$ & $\begin{array}{l}\mathrm{Q}_{\text {Tloss }} \\
\text { (Mvar) }\end{array}$ & $\begin{array}{l}\mathrm{P}_{\mathrm{gT}} \\
(\mathrm{MW})\end{array}$ & $\begin{array}{l}\mathrm{P}_{\text {Tloss }} \\
(\mathrm{MW})\end{array}$ & $\begin{array}{l}\text { Size of } \\
\text { particle } \\
\text { (SVC) }\end{array}$ & $\begin{array}{l}\text { Position } \\
\text { (Bus No) }\end{array}$ \\
\hline \multirow[t]{6}{*}{ PSO } & 1 & 38.278 & 31.474 & 36.741 & 15.953 & 23.570 & 145.408 & 68.740 & 300.600 & 17.438 & 72.438 & 13 \\
\hline & 1.1 & 33.614 & 29.032 & -2.482 & 12.096 & 7.433 & 162.539 & 84.037 & 305.419 & 22.019 & 99.926 & 6 \\
\hline & 1.2 & 47.362 & 35.922 & 31.549 & 12.727 & 4.855 & 182.241 & 105.003 & 310.271 & 26.871 & 46.469 & 4 \\
\hline & 1.3 & 41.461 & 31.475 & 29.216 & 10.384 & 6.642 & 211.425 & 134.704 & 318.792 & 35.392 & 82.179 & 4 \\
\hline & 1.4 & 34.347 & 38.749 & 38.129 & 16.714 & 8.453 & 238.060 & 160.431 & 325.531 & 42.131 & 82.414 & 4 \\
\hline & $\mathrm{X} / \mathrm{R} 4$ & 48.365 & 37.225 & 35.553 & 5.223 & 4.564 & 237.972 & 158.998 & 304.710 & 21.310 & 40.408 & 23 \\
\hline \multirow[t]{3}{*}{ NR } & 1 & 48.341 & 36.220 & 32.271 & 17.208 & 11.364 & 147.510 & 69.062 & 301.006 & 17.606 & - & - \\
\hline & 1.1 & 48.357 & 35.164 & 26.230 & 23.334 & 18.722 & 166.499 & 87.200 & 305.514 & 22.114 & - & - \\
\hline & 1.2 & 38.772 & 41.412 & 31.676 & 24.357 & 25.183 & 187.180 & 107.060 & 310.686 & 27.286 & - & - \\
\hline
\end{tabular}


Table 2. Real and Reactive power Generation, losses, SVC size and Bus No under generator outage condition in PSO method

\begin{tabular}{|c|c|c|c|c|c|c|c|c|c|c|c|c|}
\hline LF & $\begin{array}{c}\mathrm{Q}_{\mathrm{g} 2} \\
\text { (Mvar) }\end{array}$ & $\begin{array}{c}\mathrm{Q}_{\mathrm{g} 5} \\
\text { (Mvar) }\end{array}$ & $\begin{array}{c}\mathrm{Q}_{\mathrm{g} 8} \\
\text { (Mvar) }\end{array}$ & $\begin{array}{c}\mathrm{Q}_{\mathrm{g} 11} \\
\text { (Mvar) }\end{array}$ & $\begin{array}{c}\mathrm{Q}_{\mathrm{g} 13} \\
\text { (Mvar) }\end{array}$ & $\begin{array}{c}\mathrm{Q}_{\mathrm{gT}} \\
\text { (Mvar) }\end{array}$ & $\begin{array}{c}\mathrm{Q}_{\text {Tloss }} \\
\text { (Mvar) }\end{array}$ & $\begin{array}{c}\mathrm{P}_{\mathrm{gT}} \\
(\mathrm{MW})\end{array}$ & $\begin{array}{l}\mathrm{P}_{\text {Tloss }} \\
(\mathrm{MW})\end{array}$ & $\begin{array}{c}\text { PartSize } \\
\text { (SVC) }\end{array}$ & $\begin{array}{l}\text { PartPos } \\
\text { (Bus No) }\end{array}$ & $\begin{array}{c}\text { No of } \\
\text { Gen out- } \\
\text { age }\end{array}$ \\
\hline 1 & - & 30.567 & 26.417 & 7.437 & -2.343 & 156.295 & 79.850 & 304.048 & 20.648 & 42.867 & 31 & Gen2 \\
\hline 1 & - & - & 17.150 & 2.482 & -4.298 & 161.042 & 85.491 & 306.067 & 22.667 & 33.519 & 3 & Gen $2 \& 5$ \\
\hline 1.1 & - & - & 28.287 & 4.320 & -1.401 & 175.689 & 100.011 & 309.414 & 26.014 & 94.351 & 4 & Gen2\&5 \\
\hline 1 & 48.341 & - & - & 17.208 & 11.364 & 147.510 & 69.062 & 301.006 & 17.606 & 45.568 & 4 & Gen5\&8 \\
\hline 1.2 & 44.377 & - & - & 6.269 & -2.345 & 184.061 & 108.004 & 310.929 & 27.529 & 52.366 & 4 & Gen5\&8 \\
\hline 1.3 & 49.242 & - & - & 18.865 & 12.263 & 205.761 & 127.672 & 316.003 & 32.603 & 46.469 & 4 & Gen5\&8 \\
\hline 1.3 & 40.805 & - & - & - & - & 213.147 & 136.758 & 319.472 & 36.072 & 70.077 & 4 & $\begin{array}{l}\text { Gen5,8, } \\
11 \& 13\end{array}$ \\
\hline
\end{tabular}

Table 3. Voltage profile at different buses in NR and PSO method under various load condition

\begin{tabular}{|c|c|c|c|c|c|c|c|c|c|c|}
\hline \multirow{2}{*}{$\begin{array}{l}\text { Bus } \\
\text { No }\end{array}$} & \multicolumn{2}{|l|}{$\mathrm{LF}=1$} & \multicolumn{2}{|l|}{$\mathrm{LF}=1.1$} & \multicolumn{2}{|l|}{$\mathrm{LF}=1.2$} & \multicolumn{2}{|l|}{$\mathrm{LF}=1.3$} & \multicolumn{2}{|l|}{$\mathrm{LF}=1.4$} \\
\hline & NR & PSO & NR & PSO & NR & PSO & NR & PSO & NR & PSO \\
\hline 1 & 1.0600 & 1.0600 & 1.0600 & 1.0600 & 1.0600 & 1.0600 & 1.0600 & 1.0600 & 1.0600 & 1.0600 \\
\hline 2 & 1.0430 & 1.0430 & 1.0330 & 1.0430 & 1.0230 & 1.0330 & 1.0030 & 1.0230 & 1.0130 & 1.0130 \\
\hline 3 & 1.0213 & 1.0276 & 1.0092 & 1.0316 & 0.9999 & 1.0133 & 0.9724 & 1.0055 & 0.9842 & 0.9958 \\
\hline 4 & 1.0124 & 1.0202 & 0.9980 & 1.0257 & 0.9871 & 1.0037 & 0.9538 & 0.9948 & 0.9692 & 0.9836 \\
\hline 5 & 1.0100 & 1.0100 & 0.9900 & 1.0100 & 0.9800 & 0.9900 & 0.9300 & 0.9700 & 0.9280 & 0.9600 \\
\hline 6 & 1.0116 & 1.0199 & 0.9943 & 1.0343 & 0.9828 & 1.0024 & 0.9443 & 0.9933 & 0.9658 & 0.9810 \\
\hline 7 & 1.0032 & 1.0082 & 0.9836 & 1.0158 & 0.9717 & 0.9875 & 0.9400 & 0.9728 & 0.9512 & 0.9603 \\
\hline 8 & 1.0100 & 1.0200 & 0.9900 & 1.0200 & 0.9800 & 1.0000 & 0.9401 & 0.9900 & 0.9700 & 0.9800 \\
\hline 9 & 1.0489 & 1.0616 & 1.0371 & 1.0587 & 1.0247 & 1.0575 & 0.9788 & 1.0620 & 1.0005 & 1.0499 \\
\hline 10 & 1.0403 & 1.0566 & 1.0257 & 1.0484 & 1.0120 & 1.0636 & 0.9655 & 1.0583 & 0.9828 & 1.0603 \\
\hline 11 & 1.0820 & 1.0520 & 1.0520 & 1.0520 & 1.0520 & 1.0820 & 1.0220 & 1.0520 & 1.0520 & 1.0520 \\
\hline 12 & 1.0561 & 1.0513 & 1.0465 & 1.0613 & 1.0381 & 1.0647 & 0.9909 & 1.0623 & 1.0124 & 1.0600 \\
\hline 13 & 1.0510 & 1.0510 & 1.0510 & 1.0510 & 1.0510 & 1.0610 & 1.0210 & 1.0510 & 1.0510 & 1.0510 \\
\hline 14 & 1.0408 & 1.0648 & 1.0289 & 1.0454 & 1.0180 & 1.0544 & 0.9691 & 1.0505 & 0.9886 & 1.0507 \\
\hline 15 & 1.0359 & 1.0583 & 1.0228 & 1.0407 & 1.0107 & 1.0555 & 0.9618 & 1.0513 & 0.9801 & 1.0543 \\
\hline 16 & 1.0422 & 1.0638 & 1.0297 & 1.0479 & 1.0182 & 1.0555 & 0.9701 & 1.0596 & 0.9892 & 1.0499 \\
\hline 17 & 1.0355 & 1.0536 & 1.0210 & 1.0424 & 1.0073 & 1.0548 & 0.9594 & 1.0658 & 0.9768 & 1.0497 \\
\hline 18 & 1.0253 & 1.0459 & 1.0102 & 1.0301 & 0.9961 & 1.0440 & 0.9459 & 1.0452 & 0.9627 & 1.0508 \\
\hline 19 & 1.0221 & 1.0416 & 1.0063 & 1.0272 & 0.9913 & 1.0409 & 0.9410 & 1.0457 & 0.9572 & 1.0570 \\
\hline 20 & 1.0259 & 1.0445 & 1.0102 & 1.0317 & 0.9955 & 1.0456 & 0.9460 & 1.0528 & 0.9624 & 1.0578 \\
\hline 21 & 1.0251 & 1.0429 & 1.0090 & 1.0314 & 0.9940 & 1.0653 & 0.9456 & 1.0600 & 0.9609 & 1.0379 \\
\hline 22 & 1.0293 & 1.0458 & 1.0131 & 1.0370 & 0.9982 & 1.0540 & 0.9529 & 1.0389 & 0.9666 & 1.0409 \\
\hline 23 & 1.0248 & 1.0430 & 1.0088 & 1.0310 & 0.9938 & 1.0510 & 0.9456 & 1.0599 & 0.9607 & 1.0370 \\
\hline 24 & 1.0146 & 1.0313 & 0.9963 & 1.0217 & 0.9797 & 1.0407 & 0.9358 & 1.0505 & 0.9449 & 1.0154 \\
\hline 25 & 1.0139 & 1.0281 & 0.9935 & 1.0246 & 0.9767 & 1.0247 & 0.9313 & 1.0465 & 0.9441 & 0.9961 \\
\hline 26 & 0.9962 & 1.0108 & 0.9735 & 1.0052 & 0.9544 & 1.0035 & 0.9061 & 1.0240 & 0.9171 & 0.9706 \\
\hline 27 & 1.0221 & 1.0346 & 1.0015 & 1.0358 & 0.9856 & 1.0249 & 0.9408 & 1.0362 & 0.9567 & 0.9966 \\
\hline 28 & 1.0101 & 1.0192 & 0.9916 & 1.0289 & 0.9796 & 1.0015 & 0.9396 & 0.9941 & 0.9620 & 0.9791 \\
\hline 29 & 1.0023 & 1.0152 & 0.9790 & 1.0141 & 0.9605 & 1.0009 & 0.9122 & 1.0103 & 0.9260 & 0.9673 \\
\hline 30 & 0.9908 & 1.0039 & 0.9660 & 1.0016 & 0.9460 & 0.9870 & 0.8956 & 0.9954 & 0.9082 & 0.9504 \\
\hline
\end{tabular}




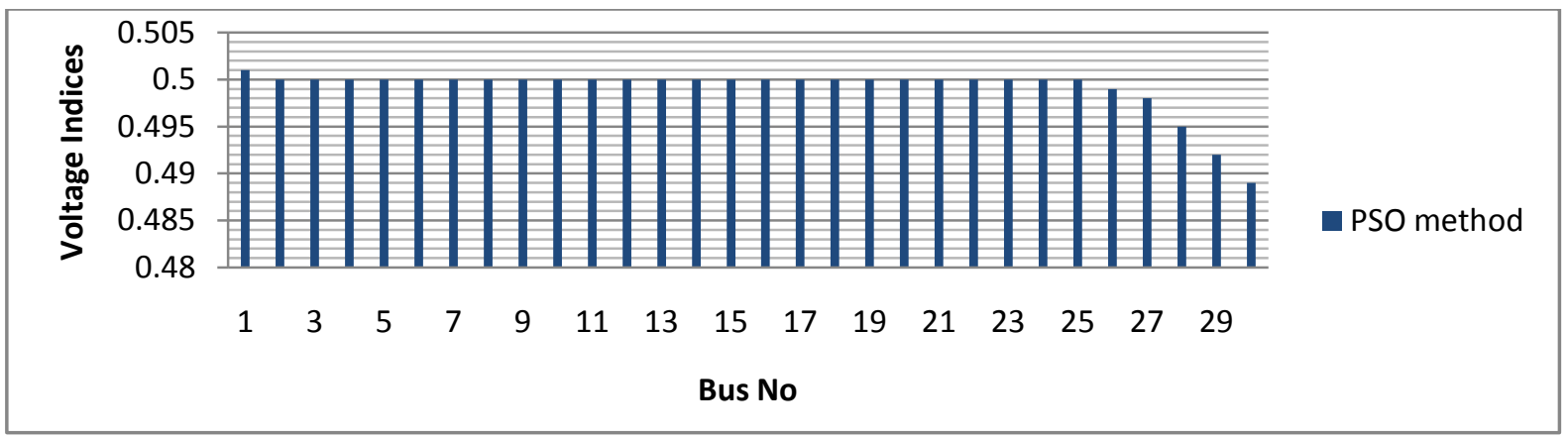

Fig 9: Voltage Indices at load buses in LF=1.2 (PSO)

Table 4. Voltage profile of different buses in PSO method in generator outage condition.

\begin{tabular}{|c|c|c|c|c|c|c|c|c|c|c|}
\hline & $\mathrm{LF}=1$ & & & & $\mathrm{LF}=1.1$ & & $\mathrm{LF}=1.2$ & & $\mathrm{LF}=1.3$ & \\
\hline BusNo & Gen2 & Gen5 & Gen2\&5 & Gen5\&8 & Gen2\&5 & Gen5\&8 & Gen2\&5 & Gen5\&8 & Gen5\&8 & $\begin{array}{l}\text { Gen5,811 } \\
\& 13\end{array}$ \\
\hline 1 & 1.0600 & 1.0600 & 1.0600 & 1.0600 & 1.0600 & 1.0600 & 1.0600 & 1.0600 & 1.0600 & 1.0600 \\
\hline 2 & 1.0330 & 1.0430 & 1.0330 & 1.0430 & 1.0330 & 1.0330 & 1.0230 & 1.0330 & 1.0230 & 1.0230 \\
\hline 3 & 1.0220 & 1.0213 & 1.0237 & 1.0213 & 1.0212 & 1.0200 & 1.0046 & 1.0155 & 1.0007 & 1.0060 \\
\hline 4 & 1.0137 & 1.0124 & 1.0158 & 1.0124 & 1.0132 & 1.0113 & 0.9934 & 1.0064 & 0.9888 & 0.9955 \\
\hline 5 & 1.0000 & 1.0100 & 1.0100 & 1.0100 & 1.0000 & 1.0000 & 0.9700 & 0.9900 & 0.9700 & 0.9700 \\
\hline 6 & 1.0133 & 1.0116 & 1.0162 & 1.0116 & 1.0131 & 1.0114 & 0.9909 & 1.0050 & 0.9848 & 0.9940 \\
\hline 7 & 1.0001 & 1.0032 & 1.0060 & 1.0032 & 0.9990 & 0.9980 & 0.9724 & 0.9891 & 0.9678 & 0.9732 \\
\hline 8 & 1.0100 & 1.0100 & 1.0100 & 1.0100 & 1.0100 & 1.0100 & 0.9900 & 1.0000 & 0.9800 & 0.9900 \\
\hline 9 & 1.0577 & 1.0489 & 1.0572 & 1.0489 & 1.0537 & 1.0664 & 1.0450 & 1.0699 & 1.0457 & 1.0652 \\
\hline 10 & 1.0581 & 1.0403 & 1.0562 & 1.0403 & 1.0508 & 1.0568 & 1.0441 & 1.0578 & 1.0492 & 1.0545 \\
\hline 11 & 1.0520 & 1.0520 & 1.0520 & 1.0520 & 1.0520 & 1.0520 & 1.0520 & 1.0520 & 1.0520 & 1.0520 \\
\hline 12 & 1.0541 & 1.0561 & 1.0566 & 1.0561 & 1.0528 & 1.0519 & 1.0528 & 1.0541 & 1.0550 & 1.0647 \\
\hline 13 & 1.0510 & 1.0510 & 1.0510 & 1.0510 & 1.0510 & 1.0510 & 1.0510 & 1.0510 & 1.0510 & 1.0510 \\
\hline 14 & 1.0674 & 1.0408 & 1.0693 & 1.0408 & 1.0508 & 1.0592 & 1.0385 & 1.0674 & 1.0425 & 1.0538 \\
\hline 15 & 1.0607 & 1.0359 & 1.0512 & 1.0359 & 1.0693 & 1.0573 & 1.0361 & 1.0516 & 1.0425 & 1.0552 \\
\hline 16 & 1.0686 & 1.0422 & 1.0577 & 1.0422 & 1.0503 & 1.0534 & 1.0403 & 1.0512 & 1.0430 & 1.0636 \\
\hline 17 & 1.0600 & 1.0355 & 1.0554 & 1.0355 & 1.0246 & 1.0220 & 1.0365 & 1.0566 & 1.0404 & 1.0514 \\
\hline 18 & 1.0609 & 1.0253 & 1.0683 & 1.0253 & 1.0639 & 1.0511 & 1.0242 & 1.0632 & 1.0290 & 1.0500 \\
\hline 19 & 1.0587 & 1.0221 & 1.0696 & 1.0221 & 1.0641 & 1.0508 & 1.0210 & 1.0618 & 1.0252 & 1.0510 \\
\hline 20 & 1.0628 & 1.0259 & 1.0555 & 1.0259 & 1.0699 & 1.0564 & 1.0258 & 1.0674 & 1.0301 & 1.0583 \\
\hline 21 & 1.0525 & 1.0251 & 1.0821 & 1.0251 & 1.0699 & 1.0565 & 1.0401 & 1.0410 & 1.0497 & 1.0664 \\
\hline 22 & 1.0507 & 1.0293 & 1.0500 & 1.0293 & 1.0547 & 1.0615 & 1.0316 & 1.0575 & 1.0380 & 1.0521 \\
\hline 23 & 1.0581 & 1.0248 & 1.0518 & 1.0248 & 1.0680 & 1.0548 & 1.0371 & 1.0572 & 1.0555 & 1.0662 \\
\hline 24 & 1.0604 & 1.0146 & 1.1017 & 1.0146 & 1.0536 & 1.0415 & 1.0148 & 1.0633 & 1.0226 & 1.0501 \\
\hline 25 & 1.0447 & 1.0139 & 1.0533 & 1.0139 & 1.0383 & 1.0299 & 1.0031 & 1.0403 & 1.0041 & 1.0531 \\
\hline 26 & 1.0275 & 0.9962 & 1.0565 & 0.9962 & 1.0192 & 1.0106 & 0.9815 & 1.0195 & 0.9807 & 1.0308 \\
\hline 27 & 1.0432 & 1.0221 & 1.0636 & 1.0221 & 1.0380 & 1.0320 & 1.0064 & 1.0361 & 1.0040 & 1.0409 \\
\hline 28 & 1.0136 & 1.0101 & 1.0178 & 1.0101 & 1.0127 & 1.0108 & 0.9896 & 1.0046 & 0.9828 & 0.9951 \\
\hline 29 & 1.0238 & 1.0023 & 1.0446 & 1.0023 & 1.0164 & 1.0103 & 0.9818 & 1.0124 & 0.9772 & 1.0152 \\
\hline 30 & 1.0126 & 0.9908 & 1.0336 & 0.9908 & 1.0039 & 0.9977 & 0.9677 & 0.9987 & 0.9617 & 1.0003 \\
\hline
\end{tabular}

Table 5. Voltage indices and power factor at different load in NR and PSO method

\begin{tabular}{|l|l|l|l|l|l|}
\cline { 2 - 6 } \multicolumn{1}{c|}{} & \multicolumn{3}{c|}{ NR } & \multicolumn{2}{c|}{ PSO } \\
\hline S.No & System LF & Pf & Index & Pf & Index \\
\hline 1 & 1 & 0.953 & 0.492 & 0.954 & 0.489 \\
2 & 1.1 & 0.941 & 0.489 & 0.926 & 0.489 \\
3 & 1.2 & 0.926 & 0.489 & 0.915 & 0.495 \\
& 1.3 & - & - & 0.907 & 0.489 \\
& 1.4 & - & - & 0.787 & 0.483 \\
& x/r Ratio=4 & & & & \\
\hline
\end{tabular}




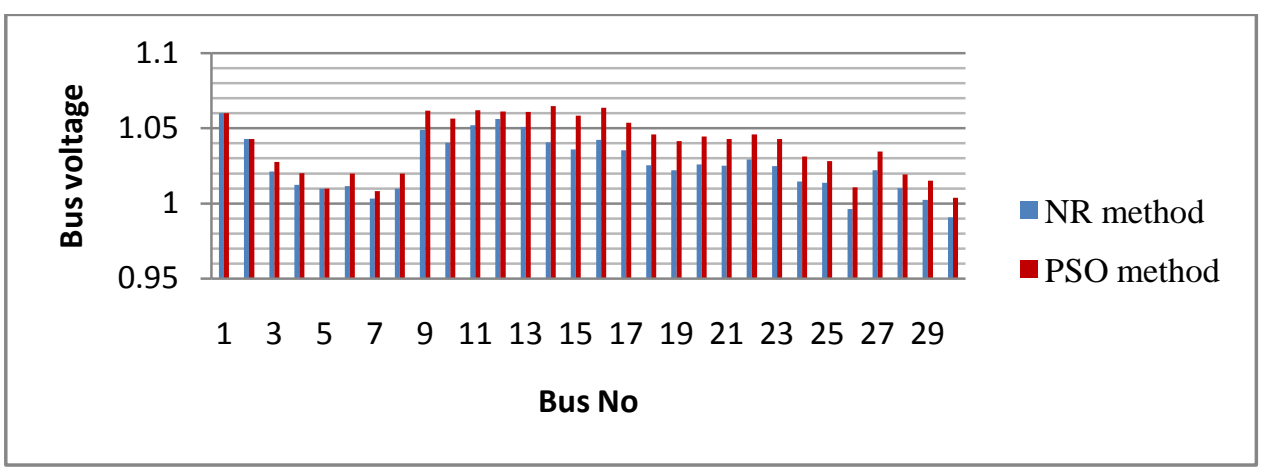

Fig3: voltage profile under base load (LF=1)

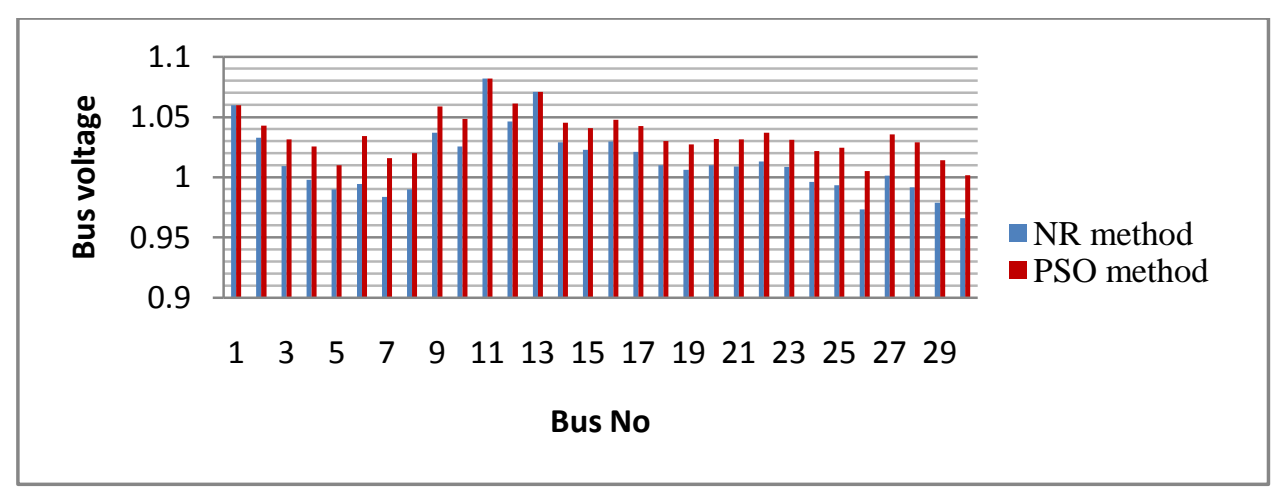

Fig 4: voltage profile under load ( $L F=1.1)$

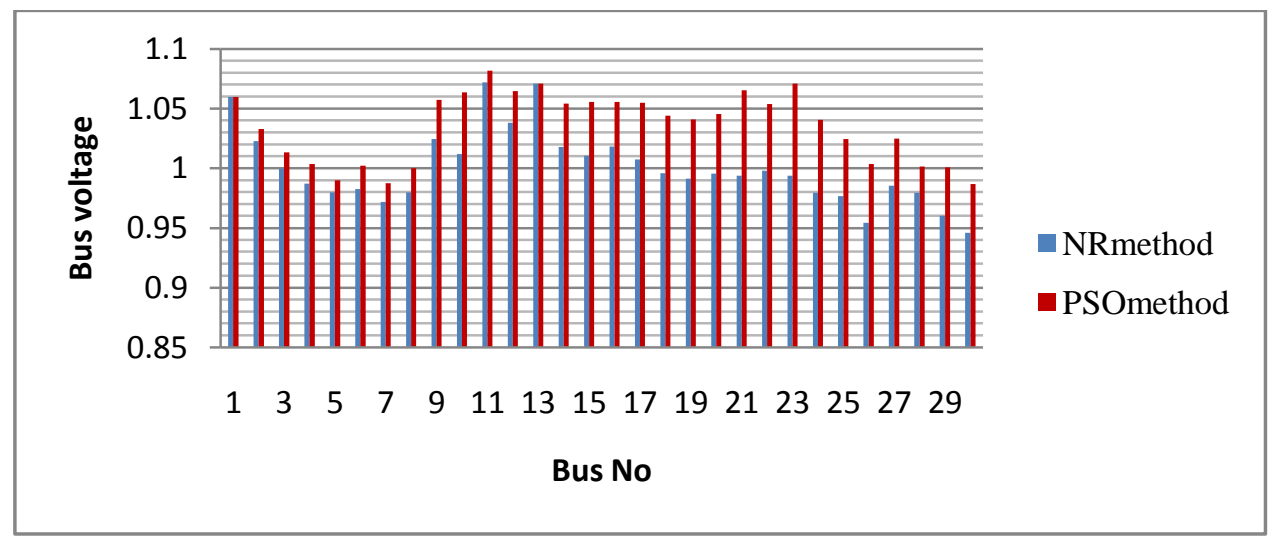

Fig 5: voltage profile under load (LF=1.2)

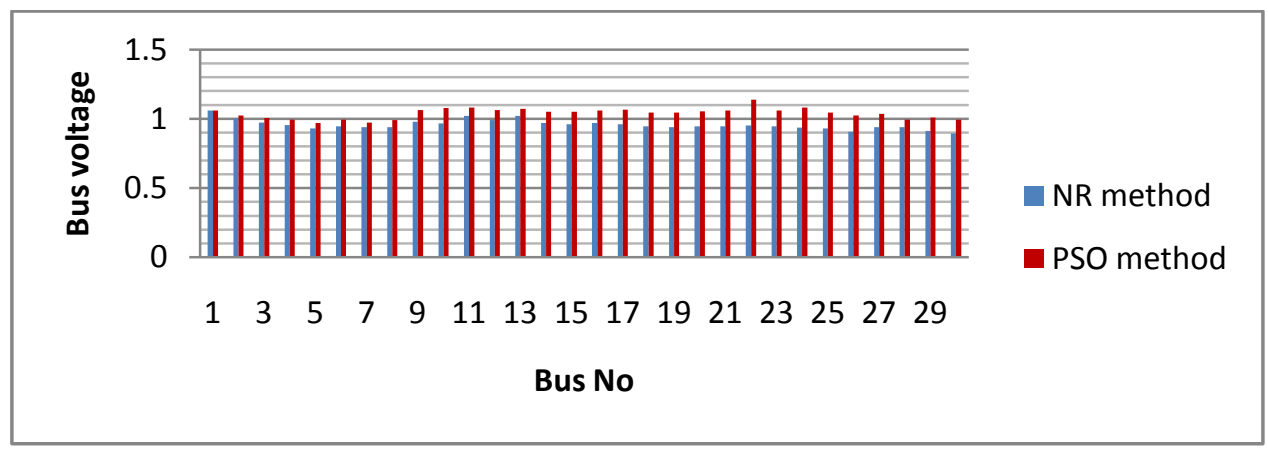

Fig 6: voltage profile under load ( $L F=1.3)$ 


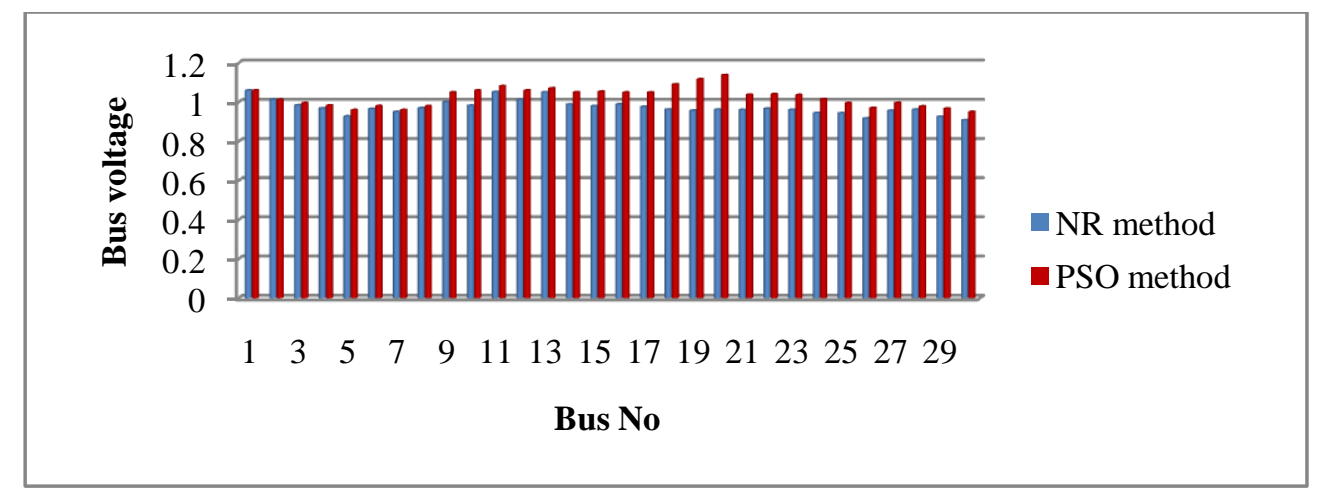

Fig7: System Voltage profile under load (LF=1.4)

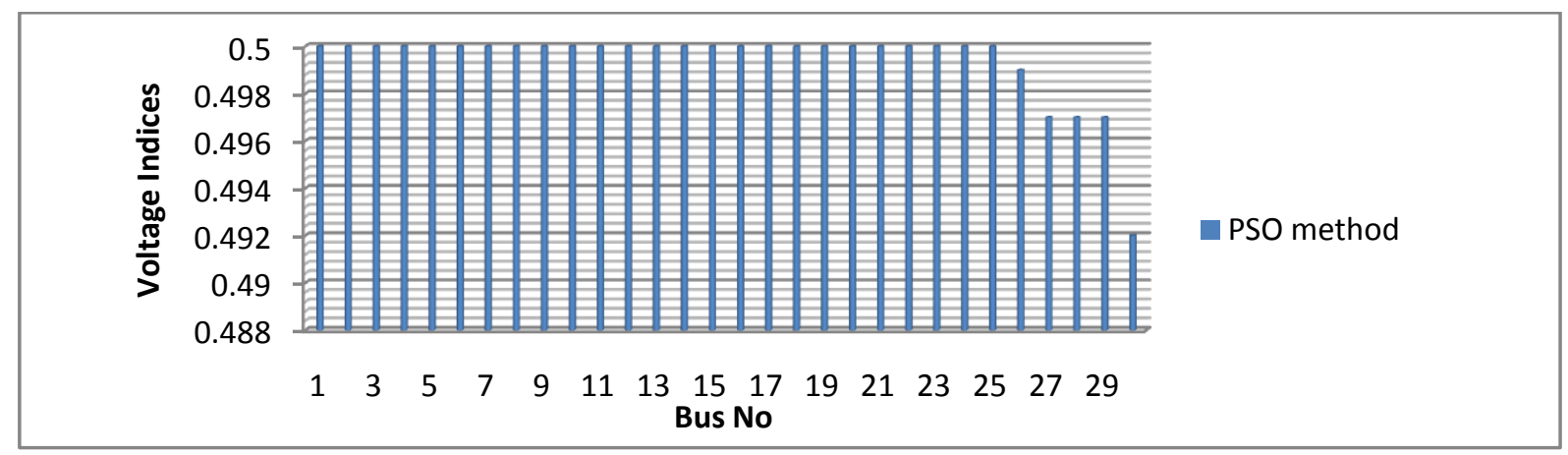

Fig8: Voltage Indices at load buses in base case (PSO)

Table 6. Real and Reactive power Generation, losses, SVC size and Bus No under load condition

\begin{tabular}{|l|l|l|l|l|l|l|l|l|l|l|l|l|l|}
\hline & $\begin{array}{l}\text { System } \\
\text { Load }\end{array}$ & $\begin{array}{c}\text { Q2 } \\
\text { Mvar }\end{array}$ & $\begin{array}{c}\text { Q3 } \\
\text { Mvar }\end{array}$ & $\begin{array}{c}\text { Q6 } \\
\text { Mvar }\end{array}$ & $\begin{array}{c}\text { Q8 } \\
\text { Mvar }\end{array}$ & $\begin{array}{c}\text { Q9 } \\
\text { Mvar }\end{array}$ & $\begin{array}{c}\text { Q12 } \\
\text { Mvar }\end{array}$ & $\begin{array}{c}\text { Q }_{\text {gT }} \\
\text { Mvar }\end{array}$ & $\begin{array}{c}\text { Q }_{\text {Tloss }} \\
\text { Mvar }\end{array}$ & $\begin{array}{c}\text { PT }_{\text {gT }} \\
\text { MW }\end{array}$ & $\begin{array}{c}\mathrm{P}_{\text {Tloss }} \\
\text { MW }\end{array}$ & $\begin{array}{c}\text { Par size } \\
\text { SVC }\end{array}$ & $\begin{array}{c}\text { ParPosi } \\
(\text { BusN o) }\end{array}$ \\
\hline NR & 1 & 0.751 & 7.369 & 6.010 & 65.386 & 6.862 & 130.745 & 328.454 & 153.755 & 1224.262 & 28.462 & - \\
& 1.1 & 2.207 & 30.355 & 15.188 & 90.438 & - & 146.190 & 385.636 & 207.539 & 1238.043 & 42.207 & - \\
& 1.2 & 18.496 & 37.196 & 14.204 & 107.02 & $\mathbf{3 . 8 1 7}$ & 134.523 & 465.589 & 283.672 & 1257.472 & 61.672 & - \\
\hline PSO & 1 & -0.775 & -0.470 & 4.369 & 63.528 & - & 121.586 & 324.789 & 155.836 & 1223.560 & 27.760 & 52.374 & - \\
& 1.1 & 7.437 & -0.445 & -3.301 & 50.149 & 1.854 & 110.561 & 341.418 & 177.908 & 1226.942 & 31.142 & 115.785 & 15 \\
& 1.2 & 7.132 & 39.175 & 12.047 & 77.472 & - & 136.717 & 463.010 & 283.021 & 1260.806 & 65.006 & 150.766 & 15 \\
& X/R & 46.868 & 14.047 & 7.663 & 70.408 & 1.783 & 78.829 & 454.758 & 284.235 & 1227.712 & 31.912 & 114.283 & 15 \\
\hline
\end{tabular}

Table 8. Voltage indices and power factor at various loading conditions

\begin{tabular}{|c|c|c|c|l|c|}
\cline { 2 - 6 } \multicolumn{1}{c|}{} & \multicolumn{3}{c|}{ NR } & \multicolumn{2}{c|}{ PSO } \\
\hline S.No & System LF & Pf & Index & Pf & Index \\
\hline 1 & 1 & 0.942 & 0.494 & 0.945 & 0.485 \\
2 & 1.1 & 0.909 & 0.493 & 0.931 & 0.493 \\
3 & 1.2 & 0.863 & 0.493 & 0.834 & 0.493 \\
4 & X/R Ratio=4 & - & - & 0.962 & 0.492 \\
& & & & & \\
\hline
\end{tabular}


Table 7. Voltage profile at different buses under various condition

\begin{tabular}{|c|c|c|c|c|c|c|}
\hline S. & \multicolumn{2}{|c|}{ LF $=1$} & \multicolumn{2}{c|}{ LF $=1.1$} & \multicolumn{2}{c|}{ LF $=1.2$} \\
\hline & NR & PSO & NR & PSO & NR & PSO \\
\hline 1 & 1.0400 & 1.0400 & 1.040 & 1.0400 & 1.040 & 1.040 \\
2 & 1.0100 & 1.0100 & 1.010 & 1.0100 & 1.010 & 1.010 \\
3 & 0.9850 & 0.9850 & 0.985 & 0.9850 & 0.975 & 0.985 \\
4 & 0.9783 & 0.9786 & 0.977 & 0.9785 & 0.966 & 0.976 \\
5 & 0.9757 & 0.9758 & 0.974 & 0.9756 & 0.963 & 0.973 \\
6 & 0.9800 & 0.9800 & 0.980 & 0.9800 & 0.970 & 0.980 \\
7 & 0.9819 & 0.9832 & 0.979 & 0.9920 & 0.972 & 0.992 \\
8 & 1.0050 & 1.0050 & 1.005 & 1.0050 & 1.005 & 1.005 \\
9 & 0.9800 & 0.9800 & 0.970 & 0.9800 & 0.970 & 0.970 \\
10 & 0.9857 & 0.9880 & 0.973 & 0.9886 & 0.958 & 0.970 \\
11 & 0.9732 & 0.9771 & 0.961 & 0.9772 & 0.952 & 0.962 \\
12 & 1.0150 & 1.0150 & 1.005 & 1.0150 & 0.985 & 0.995 \\
13 & 0.9779 & 0.9821 & 0.967 & 0.9837 & 0.952 & 0.967 \\
14 & 0.9688 & 0.9748 & 0.957 & 0.9774 & 0.941 & 0.962 \\
15 & 0.9871 & 0.9909 & 0.980 & 0.9924 & 0.966 & 0.982 \\
16 & 1.0133 & 1.0134 & 1.002 & 1.0126 & 0.982 & 0.990 \\
17 & 0.9751 & 1.0175 & 1.009 & 1.0163 & 0.995 & 0.999 \\
18 & 0.9515 & 0.9612 & 0.969 & 0.9776 & 0.953 & 0.972 \\
19 & 0.9497 & 0.9639 & 0.935 & 0.9694 & 0.918 & 0.957 \\
20 & 1.0004 & 1.0227 & 0.983 & 1.0487 & 0.959 & 1.038 \\
21 & 1.0029 & 1.0263 & 0.985 & 1.0538 & 0.961 & 1.043 \\
22 & 1.0010 & 1.0242 & 0.983 & 1.0583 & 0.959 & 1.049 \\
23 & 0.9842 & 1.0045 & 0.965 & 1.1507 & 0.940 & 1.173 \\
24 & 0.9378 & 0.9713 & 0.910 & 1.0824 & 0.876 & 1.091 \\
25 & 0.9453 & 0.9632 & 0.928 & 1.0906 & 0.906 & 1.110 \\
26 & 0.9727 & 0.9816 & 0.961 & 1.0428 & 0.946 & 1.049 \\
27 & 0.9896 & 0.9951 & 0.981 & 1.0324 & 0.969 & 1.035 \\
& 0.9727 & 0.9816 & 0.961 & 1.0428 & 0.946 & 1.049 \\
\hline
\end{tabular}

\begin{tabular}{|l|l|l|l|l|l|l|}
\hline 28 & 0.9896 & 0.9951 & 0.9815 & 1.0324 & 0.9696 & 1.0350 \\
29 & 1.0043 & 1.0076 & 0.9982 & 1.0309 & 0.9887 & 1.0318 \\
30 & 0.9201 & 0.9579 & 0.8904 & 1.0583 & 0.8525 & 1.0623 \\
31 & 0.8999 & 0.9475 & 0.8666 & 1.0199 & 0.8245 & 1.0140 \\
32 & 0.9259 & 0.9857 & 0.8953 & 1.0141 & 0.8566 & 1.0021 \\
33 & 0.9236 & 0.9835 & 0.8927 & 1.0119 & 0.8535 & 0.9995 \\
34 & 0.9491 & 1.0217 & 0.9245 & 0.9964 & 0.8934 & 0.9752 \\
35 & 0.9575 & 1.0310 & 0.9341 & 1.0014 & 0.9044 & 0.9808 \\
36 & 0.9682 & 1.0264 & 0.9462 & 1.0098 & 0.9182 & 0.9905 \\
37 & 0.9778 & 1.0265 & 0.9571 & 1.0184 & 0.9303 & 1.0006 \\
38 & 1.0071 & 1.0311 & 0.9900 & 1.0464 & 0.9667 & 1.0331 \\
39 & 0.9758 & 1.0241 & 0.9549 & 1.0160 & 0.9279 & 0.9976 \\
40 & 0.9653 & 1.0226 & 0.9431 & 1.0061 & 0.9151 & 0.9863 \\
41 & 0.9938 & 1.0117 & 0.9761 & 1.0053 & 0.9584 & 0.9865 \\
42 & 0.9631 & 0.9879 & 0.9409 & 0.9792 & 0.9174 & 0.9553 \\
43 & 1.0083 & 1.0161 & 0.9945 & 1.0143 & 0.9821 & 0.9980 \\
44 & 1.0121 & 1.0320 & 0.9970 & 1.0442 & 0.9755 & 1.0315 \\
45 & 1.0334 & 1.0446 & 1.0244 & 1.0510 & 1.0089 & 1.0432 \\
46 & 1.0570 & 1.0691 & 1.0436 & 1.0753 & 1.0244 & 1.0613 \\
47 & 1.0292 & 1.0465 & 1.0135 & 1.0561 & 0.9917 & 1.0416 \\
48 & 1.0229 & 1.0418 & 1.0066 & 1.0530 & 0.9843 & 1.0384 \\
49 & 1.0328 & 1.0478 & 1.0163 & 1.0558 & 0.9945 & 1.0389 \\
50 & 1.0207 & 1.0320 & 1.0026 & 1.0367 & 0.9798 & 1.0151 \\
51 & 1.0513 & 1.0555 & 1.0364 & 1.0568 & 1.0187 & 1.0360 \\
52 & 0.9676 & 0.9703 & 0.9553 & 0.9871 & 0.9425 & 0.9779 \\
53 & 0.9546 & 0.9569 & 0.9397 & 0.9704 & 0.9260 & 0.9569 \\
54 & 0.9866 & 0.9879 & 0.9730 & 0.9952 & 0.9646 & 0.9824 \\
55 & 1.0276 & 1.0279 & 1.0164 & 1.0295 & 1.0143 & 1.0193 \\
56 & 0.9641 & 0.9938 & 0.9414 & 0.9843 & 0.9163 & 0.9608 \\
57 & 0.9600 & 0.9932 & 0.9366 & 0.9833 & 0.9099 & 0.9595 \\
\hline
\end{tabular}

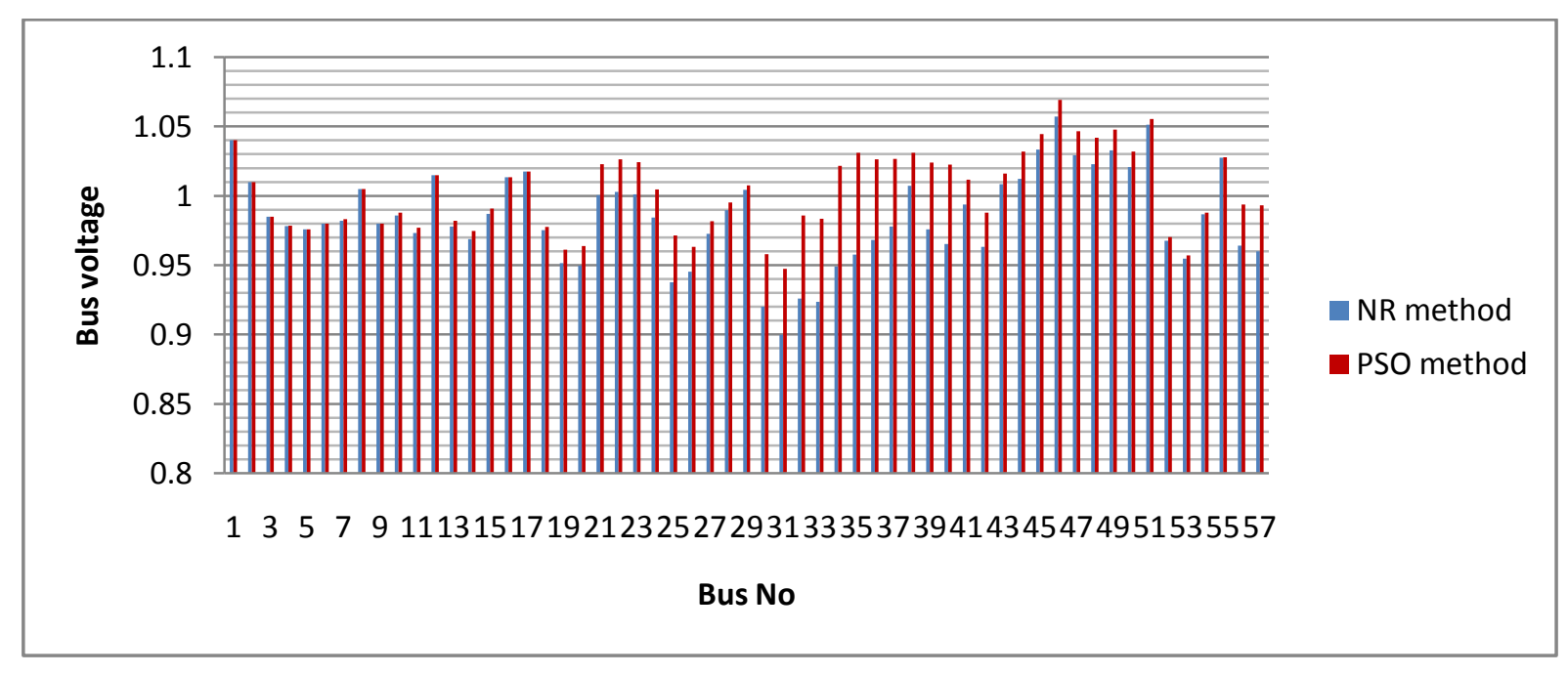

Fig 10: System voltage profile under base load (LF =1) 




Fig11: System voltage profile under load (LF =1.1)

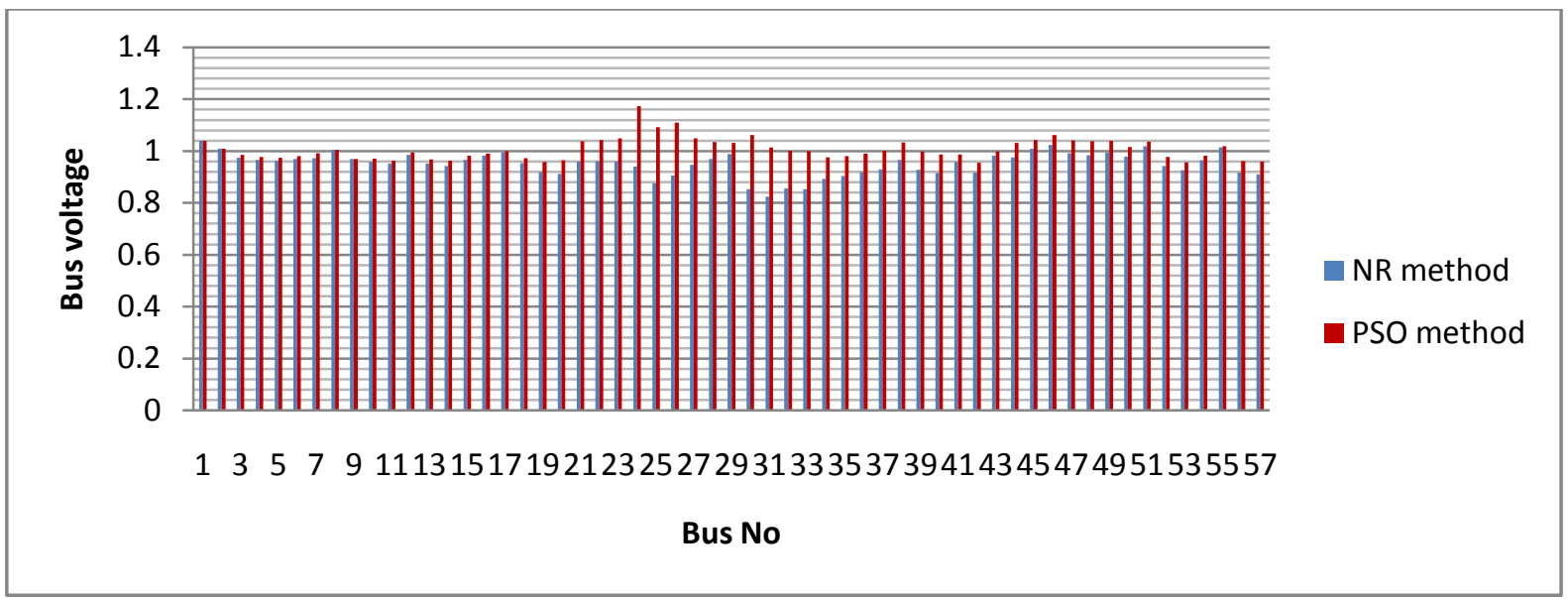

Fig12: System voltage profile under load (LF =1.2)

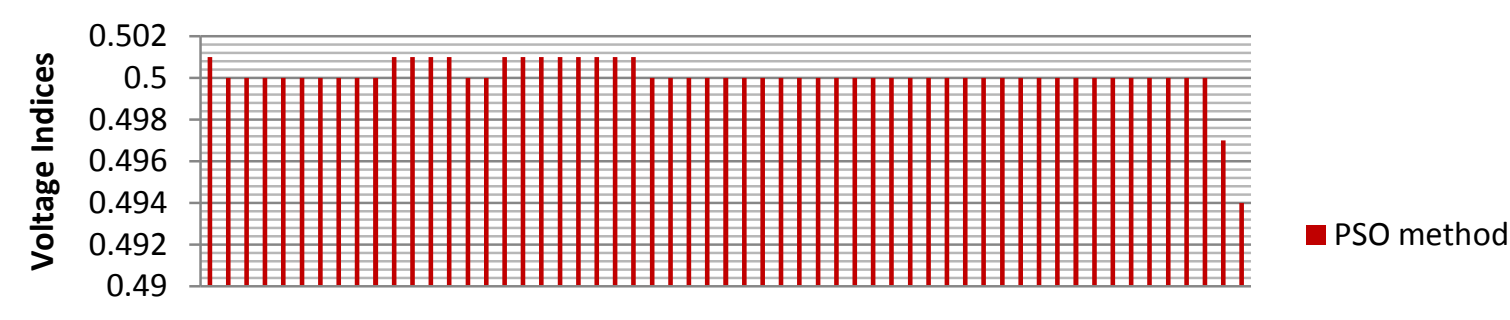

13579111315171921232527293133353739414345474951535557

Bus No

Fig13: Voltage Indices in PSO method under load condition ( $L F=1.2)$

\section{CONCLUSION}

In this work the reactive reserve has been maintained and the voltage collapse point enhanced by the proper location and sizing of the SVC device using PSO. The generators are generating lesser amount of reactive power for the suitable location of SVC under various load condition the saving is 20 percent from the system total reactive power generation. The real and reactive power losses are reduced noticeably and Voltage in the buses and power factor is maintained within the limit under generator outage contingency condition also. The voltage stability index used in the work is a good candidate to determine the voltage collapse point under loaded condition

\section{BIOGRAPHIES}

A.Subramanian received B.E., degree in Electrical and Electronics Engineering from Annamalai University in 1995. M.Tech., from Pondicherry central University 
in 2004 and now pursuing Ph.D at Anna University Trichirapalli Trichy. At present he is working as professor in V.R.S College of Engineering and Technology Arasur Villupuram Tamil Nadu.His field of interest are power system Reactive Power Reserve Management, Voltage Stability and Optimization Technique.

G. Ravi received B.E., degree in Electrical \& Electronics Engineering from Mysore University in 1992. M.E.,from Annamalai University in 1994 and Ph.D (Engg) from Jadavpur University in 2005. At present he is a faculty in Electrical \& Electronics Engineering department at Pondicherry Engineering College, Pondicherry. His research area includes electrical machines, power system operation, planning, optimization and soft computing techniques.

\section{REFERENCES}

[1] P.Kessel, H.Glavitsch "Estimating the voltage stability of a power system". IEEE Trans Power Delivery 1986; PWRD-1(3):346-354.

[2] H.K.Clark "New challenges: voltage stability". IEEE Power ENG. Rev 1990; April: 33-37.

[3] A.K.Sinhaa, D.A. Hazarikab "Comparative study of voltage stability indices in a power System" Electrical Power and Energy Systems $22(2000)$ 589-596.

[4] Antonio C.Andrade, F.P.Maciel Barbosa "FSQV and Artificial Neural Networks to Voltage Stability Assessment" IEEE 2006 IEEE PES Transmission and Distribution Conference and Exposition Latin America, Venezuela.

[5] P.Nedwick, A. F. Mistr Jr., and E. B. Croasdale, Reactive management a key to survival in the 1990s," IEEE rans. Power Syst., vol. 10, no. 2, pp. 1036-1043, May 1995.

[6] Narain G.Hingorani, L.Gyugyi "Understanding FACTS: Concepts and Technology of Flexible AC Transmission Systems".IEEE Press, 2000, ISBN0-7803- 345508.

[7] A.Caiiizares Zeno T Faur "Analysis of SVC and TCSC Controllers in Voltage Collapse".IEEE Transactions on Power Systems, Vol. 14, No. 1, February 1999.

[8] C.J.Parker I.F. Morrison, D. Sutanto "Application of an Optimisation Method for Determining the Reactive
Margin from Voltage Collapse in Reactive Power Planning” IEEE Transactions on Power Systems, Vol. 11, No. 3, August 19961473

[9] Muhammad Waseem Younas and Suhail A.Qureshi Voltage Stability Improvement of a reactive Power Constrained Longitudinal Network Feeding predomianty Agricultural loads in scattered remote areas 2008 Australasian Universities Power Engineer ing conference (AUPEC'08).

[10] Yakout Mansour Wilsun $\mathrm{Xu}$ Fernando Alvarado Chhewang Rinzin B.C" SVC Placement using critical modes of Voltage instability".IEEETransactions on Power Systems. Vol. 9. No. 2. May 1994 pp 757.

[11] Nemat Talebi M. Ehsan, S.M.T. Bathaee "Effects of SVC and TCSC Control Strategies on Static Voltage Collapse Phenomena" 2004 IEEE Conference.

[12] Sidhartha Panda ,Narayana Prasad Padhy"Comparison of particle swarm optimization and genetic algorithm for FACTS-based controller design "Applied Soft Computing 8 (2008) 1418-1427.

[13] Z.LGaing“A particle swarm optimizationapproach for Optimum design of PID Controller in AVR system" IEEE Trans. Energy Conv. 9(2) (2004) 84-391.

[14] M.Saravanan, S.Mary Raja Slochanal, P.Venkatesh, J.Prince Stephen Abraham "Application of particle Swarm optimization technique for optimal location of FACTS devices considering cost of installation and system loadability".Electric power systems Research 77(2007) 276-283.

[15] Y.Del Valle, G. K. Venayagamoorthy “ ptimal STATCOM Sizing and Placement Using Particle Swarm Optimization" 2006 IEEE Conference.

[16] Dr.N.Venkata Ramana and K.Chandrasekar "MultiObjective Genetic Algorithm to mitigate the composite problem of total transfer capacity,voltage stability and transmission loss minimization" IEEE conference 2007. 